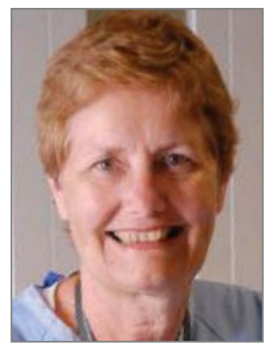

Judith Clements

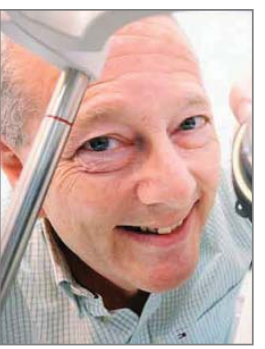

Nathan Efron

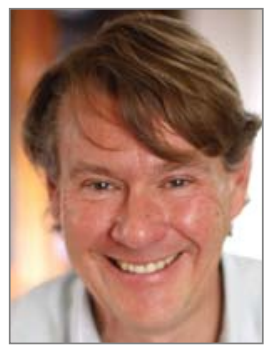

Stephen Simpson

Cate Swannell

$\mathrm{BA}$

MJA Engagement/ News Editor

doi: 10.5694/mja15.n0615

\title{
Health professionals feature in honours
}

\section{Doctors and medical researchers have featured prominently in this year's Queen's Birthday honours list announced last Monday}

Four medical professionals were named as Companions in the General Division of the Order of Australia (AC). They are:

Distinguished Professor Judith Clements: For eminent service to the biological sciences and to education, through seminal contributions to improving the understanding of cancers, particularly prostate cancer, as an advocate for the development of biomedical research facilities, and to the training of scientists.

Professor Nathan Efron: For eminent service to medicine in the field of clinical optometry, particularly to vision correction and corneal physiology, as an academic, researcher and author, to the treatment of juvenile diabetes, and through executive roles with national and international professional organisations.

Professor Stephen Lynch: For eminent service to medicine, particularly through major advancements in the area of liver transplantation surgery and science, as a leading clinician, to medical education and training at a national and international level, and to professional organisations.

Professor Stephen Simpson: For eminent service to biological and biomedical science as an educator, researcher and author, particularly in the areas of human nutrition, obesity and metabolic disease, to higher education, and through roles with a range of professional scientific organisations.

\section{Officer in the General Division (AO)}

Dr Barry Allen: For distinguished service to biomedical physics, radiation oncology and the development of innovative methods of cancer treatment, and to international scientific associations.

Professor Paolo Ferrari: For distinguished service to medicine in nephrology, as a clinician scientist, to the establishment of innovative renal transplantation programs, and to medical education.

Dr Richard Gun: For distinguished service to medicine, particularly in the field of occupational health and safety, and to socially disadvantaged communities in regional Australia and Timor-Leste.

Professor Douglas Henderson: For distinguished service to medicine, particularly anatomical pathology, and to education as an academic and author in the field of asbestos-related diseases.

Professor Nigel Laing: For distinguished service to medicine in the field of neuromuscular disorders, as an academic and researcher, to medical education, and through contributions to professional associations.

Dr Hugh Niall: For distinguished service to biomedical science, in the field of hormone sequencing, to higher education and research commercialisation, and to student development programs.
Dr Lynette Roberts, AM: For distinguished service to community health through executive and governmental advisory roles aimed at improving cardiovascular wellbeing.

Professor Karen Simmer: For distinguished service to medicine in paediatrics, particularly neonatal and perinatal nutrition, to medical education, as a researcher and clinician, and to the community.

Professor Marelyn Wintour-Coghlan: For distinguished service to medical science in physiology, particularly in maternal and child health, to education, and to professional organisations.

\section{Member in the General Division (AM)}

Professor Bruce Brew; Dr Gordon Cable; Dr Russell Clark; Dr Catherine Crock; Professor Ian Gough; Professor Ian Harris; Dr Hugh Hazard; Professor Annemarie Hennessy; Clinical Professor Richard Herriman; Professor Ross Holland; Dr Alan Isaacs; Dr Jennifer Johns; Dr Anthony Keller; Dr Michael Lanigan; Dr Paul Luckin; Professor Robert Lusby; Associate Professor John Mackay; Professor Murray Norris; Dr Clifford Pollard; Dr Robert Roy; Professor John Seymour.

\section{Medal in the General Division (OAM)}

Dr Adel Asaid; Dr John Blackwell; Professor Niki Ellis; Dr Philip Godden; Dr David Hollands; Dr David Howe; Associate Professor Alyson Kakakios; Dr Colin MacArthur; Dr Brian Norcock; Dr Nicholas O'Ryan; Dr Shiva Prakash; Dr Geoffrey Smith; Dr Tuck Meng Soo.

\section{Public Service Medal}

Dr Kerry Chant: For outstanding public service to population health in New South Wales. Dr Chant has been an effective and active leader in the field of public health for the past 23 years. She has shown a commitment to the delivery of world-class public health services through expertise in communication and responsiveness during a public health crisis.

Dr Edward Strivens: For outstanding public service to Queensland Health. Dr Strivens is the Clinical Director of Older Persons Sub-acute and Rehabilitation Service for the Cairns and Hinterland Hospital and Health Service. In his area of expertise he exhibits an exceptional ability to understand the complex needs of our ageing population.

Dr Jeanette Young: For outstanding public service to Queensland Health. Dr Young has made a major contribution to improving the health of Queenslanders for over 20 years, both through the clinical and corporate health sector. Her commitment to her work, particularly in the area of disaster medicine and medical administration, is highly regarded. 


\section{NHMRC initiatives to improve access to research outputs and findings}

The National Health and Medical Research Council (NHMRC) funds about $\$ 850$ million of Australia's best medical research each year. To continuously deliver tangible health benefits to the Australian community, NHMRC has implemented a suite of initiatives to maximise the returns from this investment.

In April 2015, NHMRC released a statement encouraging its funded researchers to improve their data sharing practices (http:/ / www.nhmrc.gov.au/grants-funding/policy/nhmrcstatement-data-sharing). The statement says:

NHMRC encourages data sharing and providing access to data and other research outputs (metadata, analysis code, study protocols, study materials and other collected data) arising from NHMRC supported research.

This is an ethos consistent with the 2007 Australian Code for the Responsible Conduct of Research (http:/ / www.nhmrc.gov.au/ guidelines-publications /r39) and a practice that stands to benefit all Australian researchers and those who fund Australian research.

NHMRC's statement on data sharing follows the NHMRC Open Access Policy (http:/ / www.nhmrc.gov.au/grants-funding/policy/ nhmrc-open-access-policy), which was implemented in July 2012 and requires that:

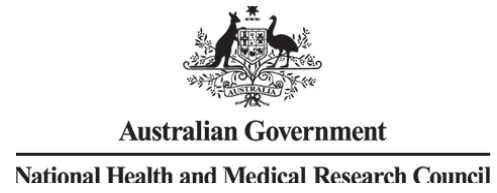

any publication arising from NHMRC supported research must be deposited into an open access institutional repository and/or made available in another open access format within a twelve month period from the date of publication.

NHMRC also requires all clinical trials it funds to be registered with a clinical trials registry.

These initiatives are aligned with the strong global movement for open access to research information. Greater transparency of research and better use and reuse of data will ensure that waste in research is minimised, while improving the reproducibility and value derived from research.

NHMRC will continue to ensure that its assessment processes are rigorous, that only the most significant research ideas are funded, and that access to research results remains as open as possible.

Wee-Ming Boon

Fiona Leves

National Health and Medical Research Council

wee-ming.boon@nhmrc.gov.au

doi: 10.5694/mjal5.00550

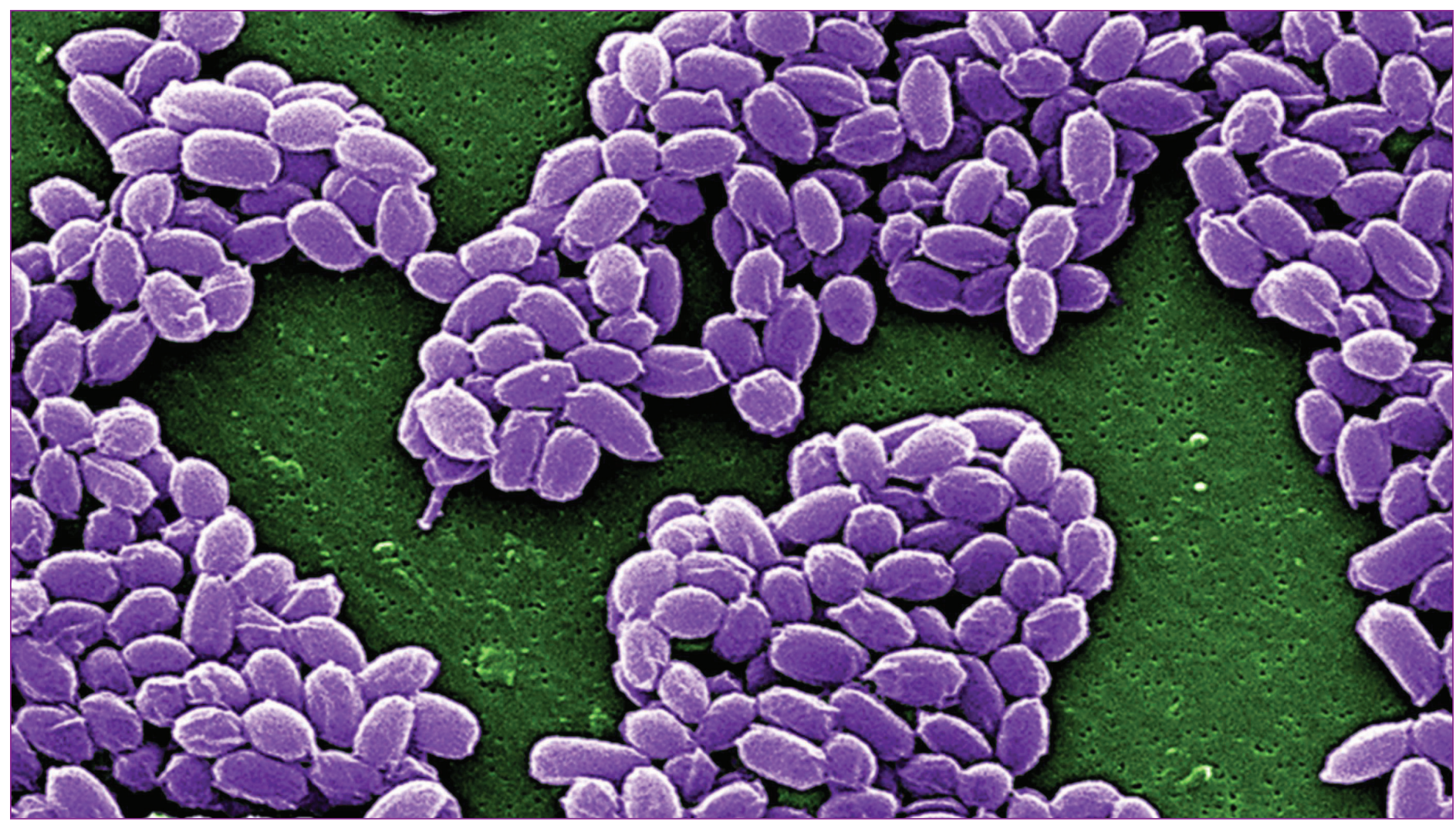

Spores from the Sterne strain of anthrax bacteria (Bacillus anthracis) are pictured in this scanning electron micrograph image. The United States military mistakenly sent live anthrax bacteria to laboratories in 11 US states and a US air base in South Korea, after apparently failing to properly inactivate the bacteria last year, US officials said. 


\section{Top 5 MJA articles online since 18 May 2015}

1) Perspective: Controversies and consensus regarding vitamin D deficiency in 2015: whom to test and whom to treat?

Controversy persists regarding who should be tested and who should be treated for vitamin $D$ deficiency doi: 10.5694/mjal4.00702

2) Research: Strengthening primary health care: achieving health gains in a remote region of Australia doi: 10.5694/mjal4.00894

3) Editorial: Rural and remote health: a progress report doi: 10.5694/mjal5.00398

4) Research: The use of financial incentives in Australian general practice doi: 10.5694/mjal4.00252

5) News (from NPS MedicineWise): Proton pump inhibitors: too much of a good thing? doi: 10.5694/mjal5.00477

\section{Meanwhile, in MJA InSight ...}

\section{College direction questioned}

"If you don't ask this kind of question, you can drift quite unconsciously to a point where you lose some of the things that are distinctive about the profession that you belong to" - Dr Simon Longstaff, executive director of the St James Ethics Centre, Sydney, NSW

https://www.mja.com.au/insight/2015/20/college-direction-questioned

\section{Community research applauded}

“There's a large body of literature on community-based participatory research, but it has been relatively underused in health" - Professor Sarah Larkins, associate dean of research at the College of Medicine and Dentistry at James Cook University,

Townsville, QLD

https://www.mja.com.au/insight/2015/20/community-research-applauded

\section{headspace data lacking}

"Because headspace is an enormous national investment, we need to be sure the real needs of young people are actually being met" - Professor lan Hickie, executive director of the Brain and Mind Research Institute, Sydney, NSW https://www.mja.com.au/insight/2015/20/headspace-data-lacking

\section{MJA Podcast}

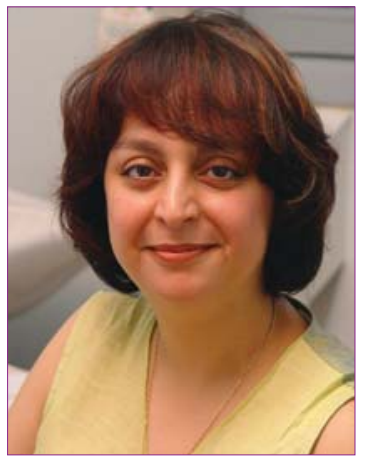

Professor Fary Khan

\section{Professor Fary Khan}

Director of rehabilitation medicine at the Royal Melbourne Hospital.

In her role as the World Health Organization's regional rehabilitation representative, she put together a six-member Foreign Medical Team to accompany her to Nepal to provide post-earthquake care. What happened there was both terrifying and life-changing. Professor Khan talks about the experience of evacuating 89 patients with severe spinal cord injuries in the middle of a major aftershock.

This podcast is available from www.mja.com.au/ multimedia/podcasts and from iTunes. It is also available as a video from www.mja.com.au/multimedia.

\section{InSight Poll}

Do you support the federal government's decision to fund a new medical school in Western Australia?

Total respondents: 156

Yes - it will provide more equitable access

Maybe - if training positions are assured

No - there are already too many graduates

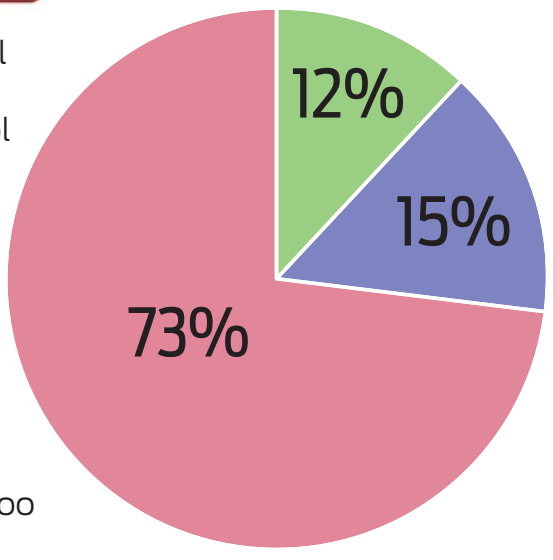

Take part in next week's poll on: www.mja.com.au/insight

\section{MJA Archive: 1995 edited extract Today's conventions of professional courtesy}

To THE EDITOR: I would like to know what is regarded today as appropriate recognition for medical treatment of a colleague.

When I graduated in 1959 it was viewed as an honour to be consulted by a colleague and no payment was expected or suggested, although the gift of a bottle of whisky was conventional.

With the coming of medical insurance and government involvement in the 1960s, a bill would be requested, and usually provided with some diffidence, on a "Strictly Medical Benefits Only" basis. This system continued satisfactorily enough over 20 years or so.

Recently, however, the expectation appears to have changed. I have received a bill for $\$ 50$ over the refund for imaging procedures and the Benefits Schedule for complex consultations. I would like to know if these expectations are routine nowadays and if they are regarded as appropriate.

Personally, I do not want my colleagues to be out of pocket for looking after me and my family, but I would find it very sad if we have abandoned the concept of professional courtesy.

Geoffrey J Long Anaesthetist, NSW 